\title{
Devastating Stroke Following Subclavian Artery Angioplasty
}

\author{
Davinder Singh Chadha ${ }^{1}$, Navreet Singh ${ }^{2}$ and Ratheesh Kumar J ${ }^{3 *}$ \\ ${ }^{1}$ Department of Cardiology, Command Hospital (Air Force), India \\ ${ }^{2}$ Department of Cardiology, Command Hospital (Western Command), India \\ ${ }^{3}$ Department of Cardiology, Command Hospital (Eastern Command), India
}

Submission:November 11, 2019; Published: December 12, 2019

*Corresponding author: Ratheesh Kumar J, West Bengal University of Health Sciences, Department of Cardiology, Command Hospital (Eastern Command), Aliporeroad, Pin: 700027, Kolkata, India

Abstract

A 65-year male with bilateral subclavian artery stenosis presented with right upper limb claudication. While undergoing angioplasty of the right subclavian artery he developed devastating stroke secondary to distal embolization. Prevention strategies for such a catastrophic event are discussed.

Keywords: Bilateral subclavian artery stenosis; Distal embolisation; Endovascular therapy; Prevention

\section{Introduction}

Atherosclerotic obstruction of the innominate artery (IA) and subclavian artery (SCA) though rare is an important cause of posterior circulation cerebral ischemia and upper limb claudication [1]. Surgical management of these lesions is technically challenging and is associated with overall complication rate of 13-19\% [1-4]. Endovascular therapies have emerged as an alternative to surgery and are increasingly preferred in view of higher initial success rate and lower rate of complications [3-5]. However distal embolization during procedure and restenosis post procedure remains an important concern. The cerebral protection devices (CPD) often used during the extra cranial carotid artery stenting to prevent distal embolization have a less established role in subclavian and innominate interventions [6]. We present here a challenging case of SCA intervention complicated with distal embolization.

\section{Case Report}

A 65-year smoker, hypertensive male and a known case of nonobstructive hypertrophic cardiomyopathy presented with chronic stable angina Class III and bilateral upper limb claudication (right $>$ left). The pulse and blood pressure in the right upper limb were unrecordable and in the left upper limb were 76 beats/min and $98 / 64 \mathrm{mmHg}$ respectively. There was a difference of $40 \mathrm{~mm}$ of $\mathrm{Hg}$ in the upper and lower limb blood pressures. There were no markers of chronic limb ischemia in the upper or lower limbs. The cardiovascular examination was normal, and examinations of the other systems were unremarkable. The electrocardiogram showed a normal sinus rhythm with features of left ventricular hypertrophy and left ventricular strain. The transthoracic echocardiogram showed moderate, symmetrical, non-obstructive myocardial hypertrophy. A Magnetic Resonance Imaging (MRI) of the brain and neck vessels revealed a common origin of the IA and left common carotid artery (CCA). There were proximal, discrete, tight occlusions of both SCA. The intracranial vessels were normal with an intact and communicative circle of Willis. There were no features of focal ischemia in the brain. For the above symptoms and signs the patient was taken up for invasive evaluation. Cardiac catheterization was undertaken and under local anesthesia (1\% xylocaine), a 7F sheath (Cordis Corporation, Miami Lakes, FL) was inserted in the right femoral artery by a modified Seldinger technique. The patient was given 5000 units of unfractionated heparin. Coronary angiogram revealed an $85 \%$, tubular, eccentric, non-calcific proximal right coronary artery (RCA) stenosis. He underwent successful angioplasty of the RCA with a $4 \times 13 \mathrm{~mm}$ PRO-Kinetic Bare Metal Stent (Biotronik, Berlin Deutschland). The aortic arch angiogram revealed presence of bovine type III configuration. A selective angiogram of the arch vessels showed bilateral $85-90 \%$ osteo-proximal, eccentric, discrete lesion of the right and left SCA (Figure 1). Bilateral extra and intracranial arteries were normal. In view of symptoms of claudication of right upper limb, it was decided to perform the angioplasty of the right SCA. The SCA lesion was initially crossed with a hydrophilic 0.014 " 
Choice PT wire (Boston Scientific, Marlborough, Massachusetts) and dilated sequentially with a $2.5 \times 15 \mathrm{~mm}$ and $4 \times 15 \mathrm{~mm}$

Maverick angioplasty balloons (Boston Scientific, Marlborough, Massachusetts).

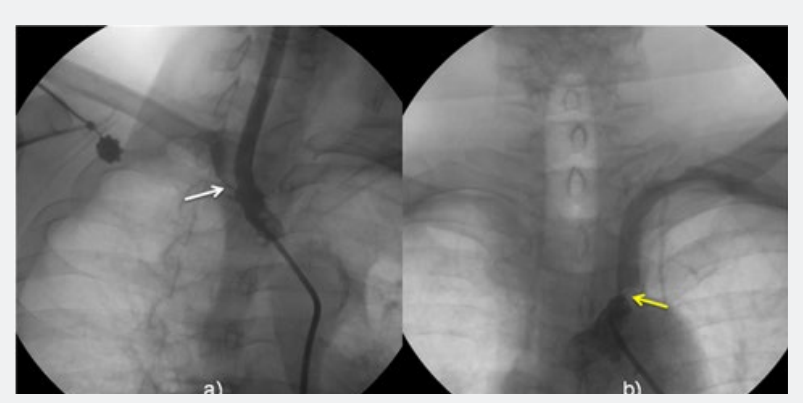

Figure 1: Selective subclavian artery (SCA) angiogram showing a) discrete stenosis of the right SCA (white arrow) b) discrete stenosis of the left SCA (yellow arrow).

The coronary wire was then exchanged with a $0.035 \times 260 \mathrm{~cm}$ J-tip taper glide wire (Terumo Cardiovascular Corp., Ann Arbor, MI). The lesion was subsequently stented with a Cordis Genesis
$7 \times 29 \mathrm{~mm}$ stainless steel stent (Cordis Corporation, Miami) at 8 atmospheres. Post angioplasty result was good with no residual stenosis (Figure 2).

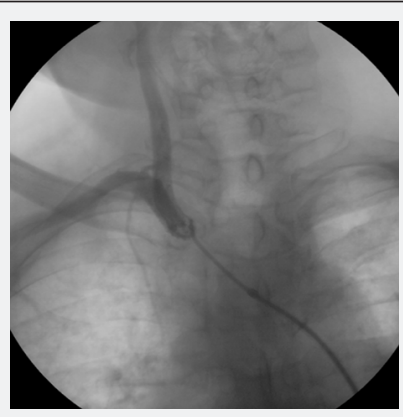

Figure 2: Selective subclavian artery (SCA) angiogram showing complete resolution of the SCA stenosis post stenting

Immediately post-procedure patient became unresponsive and examination revealed dense left sided hemiplegia. Angiogram of the intra and extra cranial vessels did not reveal any obstructive lesion. An urgent computed tomogram ruled out intracranial hemorrhage. The activated clotting time recorded in the cardiac catheterization laboratory was $268 \mathrm{sec}$. Patient was shifted to intensive care unit and started on supportive therapy. There was no improvement in his clinical state and a diffusion weighted MRI done 24 hrs post procedure showed features of an acute infarct in both cerebelli and the right middle cerebral artery (MCA) territory (Figure 3). Despite optimal care he succumbed to the above complication on the 3 rd post angioplasty day.

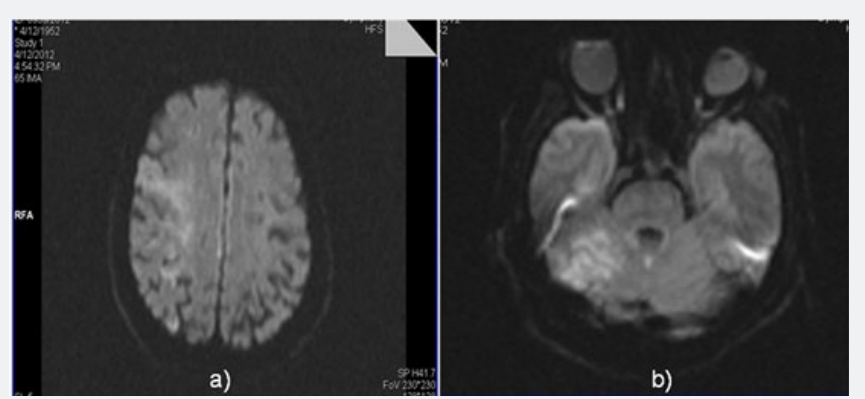

Figure 3: Restricted diffusion magnetic resonance images showing infarct in the (a) right middle cerebral artery region and (b)right and left cerebellum.

\section{Discussion}

The overall occurrence of significant SCA and IA stenosis is around 0.5 to $2 \%$ with the left SCA being affected fourfold higher than the right side [4]. Anatomically the proximal SCA lesions account for $70-90 \%$ of all cases [5]. Associated, coronary artery disease is known to affect over $50 \%$ cases of symptomatic SCA 
occlusions, with over $25 \%$ necessitating revascularization [4]. Over the past few decades rapid advances in hardware and technique have made endovascular management as the first line of treatment for SCA/IA occlusive disease [3-5]. Indications for treatment include clinical symptoms ranging from transient ischemic attacks, stroke, subclavian steal syndrome or upper limb claudication. Intervention in IA is often challenging due to its large diameter, short length and bifurcation pattern into the right CCA and SCA.

Our case not only had bilateral SCA stenosis, but also a significant RCA occlusion. The complexity of the lesion in the present case was further compounded by presence of abnormal configuration of the aortic arch, where in the IA and the left CCA had a common origin. Complications, though infrequent (2-9\%) are either local due to access vessel site injury, or remote due to neurological affection $[3,4]$. Neurological complications present as strokes (2.2\%-9\%) due to vessel occlusion by arterial dissection, thrombosis or embolization [3,4]. Apart from optimal use of antithrombotic and antiplatelet agents the rate of embolization during IA / SCA intervention is governed by atherosclerotic plaque burden at the ostium and arch anatomy. Neuroprotection by distal embolic protection (DEP) devices have been infrequently used in some cases while performing SCA/IA angioplasty to prevent distal embolization [6]. A careful consideration of using DEP was done in the present case; however it was decided against using the same in view of the challenging anatomy (bovine type III configuration of the aortic arch) which would have mandated placement of 03 DEP devices (one in each of the carotids and one in the vertebral artery). It would have been impossible to stent the SCA without jailing one of the devices. The rate of embolization in vertebral arteries is regulated by the pattern of flow in the vessel; being higher in those with antegrade flow. In vessels with tight stenosis reversal of flow after recanalization is known to persist for up to 30sec thereby protecting against embolism [6]. Flow reversal in the vertebral arteries can be enhanced prior to stenting by performing repetitive handgrip exercise. However, in the present case contralateral SCA stenosis may have been the factor preventing flow reversal by impeding the antegrade flow in the left vertebral artery. Our patient sustained a multi-vessel fatal stroke because of embolic occlusion of the intracranial vessels. The embolic shower likely occurred antegrade through the right vertebral artery and then spread to the other intracranial vessels through the circle of Willis. This complication noted in the present case has to be considered as a one-off case and cannot determine a change in the standard protocol of IA/SCA angioplasty. However, this needs to be kept in mind and consent for the same taken from the patients and their relatives while performing similar procedure.

\section{Conclusion}

SCA angioplasty may be complicated with rare occurrence of stroke and death. Prevention strategies for such rare, unpredictable and catastrophic events remain debatable and needs to be decided on a case to case basis.

\section{References}

1. Mufty H, Janssen A, Schepers S (2014) Dealing with symptomatic stenosis of the subclavian artery: Open or endovascular approach? A case report. Int J Surg Case Rep 5(8): 441-443.

2. Reyna J, Peguero JG, Elmahdy HM, Santana O, Conde C (2014) Subclavian artery stenosis: a case series and review of the literature. Rev Cardiovasc Med 15(2): 189-195.

3. Stone PA, Srivastiva M, Campbell JE, Mousa AY (2010) Diagnosis and Treatment of Subclavian Artery Occlusive Disease. Expert Rev Cardiovasc Ther 8(9): 1275-1282.

4. Norgren L, Hiatt WR, Dormandy JA, Nehler MR, Harris KA, et al. (2007) Inter-society consensus for the management of peripheral arterial disease (TASC II). J Vasc Surg 4(Suppl. S): S65-S67.

5. Sixt S, Rastan A, Schwarzwalder U, Bürgelin K, Noory E, et al. (2009) Results after balloon angioplasty or stenting of atherosclerotic subclavian artery obstruction. Cathet Cardiovasc Interv 73(3): 395403.

6. Albuquerque FC, Ahmed A, Mitha A, Stiefel M, McDougall CG (2013) Endovascular recanalization of the chronically occluded brachiocephalic and subclavian arteries: technical considerations and an argument for embolic protection. World Neurosurg 80(6): e327-e336.

\section{Your next submission with Juniper Publishers will reach you the below assets}

- Quality Editorial service

- Swift Peer Review

- Reprints availability

- E-prints Service

- Manuscript Podcast for convenient understanding

- Global attainment for your research

- Manuscript accessibility in different formats

( Pdf, E-pub, Full Text, Audio)

- Unceasing customer service

Track the below URL for one-step submission https://juniperpublishers.com/online-submission.php 